$\begin{array}{cc}\text { ACADEMIA ROMÂNĂ } & \text { Rev. Roum. Chim., } \\ \text { 2020, 65(4), 403-406 }\end{array}$

Note

\title{
SEPARATION AND SYNTHESIS OF THE NEW DSFs ${ }^{* *}$
}

\author{
Chun-Bin TAN, ${ }^{a}$ Chang-Qin CHANG, ${ }^{\mathrm{b}}$ Chun-Lan HE, ${ }^{\mathrm{c}}$ Lian-Hui ZHANG ${ }^{\mathrm{b}, *}$ and Xiao-Ling LIU ${ }^{\mathrm{a}, *}$

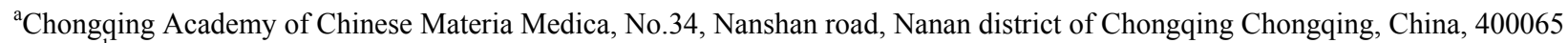 \\ ${ }^{b}$ South China Agricultural University, The Center of Microbiology Research, South China Agricultural University, \\ Wushan, Tianhe district of Guangzhou 510642 \\ ${ }^{\mathrm{c}}$ Chongqing Institute of Food and Drug Control, Chongqing 401121, China
}

Received February 19, 2020

The three active compounds of DSF (the diffusible signal factor) family were purified from the culture fluid of rpfC (enzyme for DSF biosynthesis) mutated Xac (X. axonopo-dis pvciWi). These structures were characterized by ${ }^{13} \mathrm{C}$ NMR, ${ }^{1} \mathrm{H}$ NMR, HMBC, COSY, HMQC, MS-ESI, and named as (Z)-2-tetradecenoic acid (EDSF), (Z)-13-methyl-2-tetradecenoic acid (FDSF) and (Z)-12-methyl-2-tetradecenoic acid (GDSF). Also, starting from the corresponding tetradecanal or its homologue, three DSFs were synthesized by two steps to confirm the molecular structures. Finally, the X-gluc (the solution of

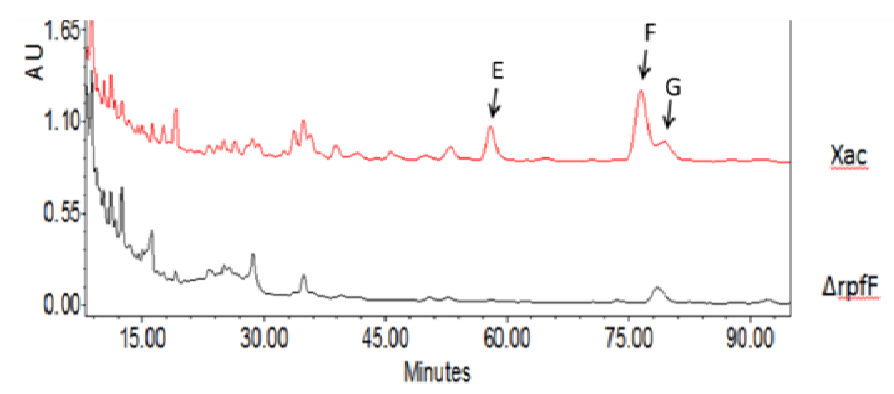
5-Bromo-4-chloro-3-indolyl- $\beta$-D-glucuronidecyclohexylam monium salt) activities of these DSFs were tested, and the activity of the compounds can be listed as follows, form the most active compound to the least active compound, FDSF $>$ GDSF $>$ EDSF.

Quorum sensing is an important way for bacteria to communicate with each other, which means that bacteria can produce and release one or more small signal molecules to the outside of the cell in a specific environment and the signal molecules can be sensed by receptors on the bacterial surface or in the cytoplasm to induce gene expression. ${ }^{1,2}$ The DSF (the diffusible signal factor), is one kind of the quorum sensing signal molecules ${ }^{3}$ and can interfere or antagonize quorum sensing effect, which was originally identified in Xanthomonas campestris pv. Campestris (Xcc) by Dr Tang. ${ }^{4}$ Xcc wild type bacteria may secrete the small molecule signal, which can induce the $\mathrm{rpfF}$ (rpf is regulation of pathogenicity factors, and rpfF is a key enzyme for DSF biosynthesis) mutant to resume the production of extracellular protease. Barber defined the signal as DSF, and considered that DSF is the unsaturated fatty acid. ${ }^{5}$ Slater established a stable, sensitive and convenient DSF detection method. ${ }^{6}$ In 2001, Professor Zhang began to study the structure and biological function of DSF. In 2004, Wang isolated and purified the DSF from the supernatant of rpfC (Another key enzyme for DSF biosynthesis) mutant culture and allowed characterization of the signal as the unsaturated fatty acid cis-11-methyl-dodecenoic acid. ${ }^{7}$

\footnotetext{
*Corresponding author:136719594@qq.com and cqszyyjy@163.com

${ }^{* *}$ Supplementary information on http://web.icf.ro/rrch/ or http://revroum.lew.ro/
} 
The $\alpha, \beta$ unsaturated double bonds determines the activity of DSF. ${ }^{8}$ BDSF and CDSF was isolated and purified from the supernatant of rice bacterial blight Xoo (Xoryzae pv. Oryzae) culture. ${ }^{9}$ Surprisingly, BDSF and CDSF have the similar biological activities with DSF, because all of them have the similar $\alpha, \beta$ unsaturated double bonds (Fig. 1). Based on this series of studies, the concept of "DSF signal family" was proposed. DSF signal structure analogues can interfere or antagonize DSF population effect, and reduce the expression of pathogenic factors to control the spread of citrus canker. This is a new way of treatment and prevention of citrus canker.

The ethyl acetate extraction from culture supernatants of the $r p f C$ mutant Xac (X. axonopo-dis pv. ciWi) was first subject to a semi-preparative HPLC and three main active fractions were collected and named as EDSF, FDSF and GDSF respectively. FDSF and GDSF were further purified by preparative silica 60 TLC (hexane/ethyl acetate $=10 / 1$ ) to remove the non-UV-active impurity. ${ }^{10}$ The DSF activity was monitored across the eluted fractions using the DSF biosensor FE58. The three peaks at $58 \mathrm{~min}, 76 \mathrm{~min}$ and $79 \mathrm{~min}$ in HPLC graph showed maximum UV absorption at $210 \mathrm{~nm}$ and strong DSF activity (Fig. 2). ${ }^{10}$ The x-gluc (the solution of 5-Bromo-4-chloro3 -indolyl- $\beta$-D-glucuronide cyclohexylammonium salt) activity of DSF signal molecule were detected ${ }^{11,12}$ (Fig. 3) ${ }^{10}$ It can be seen that the blue circle of FDSF is the largest in activity detection, indicating that DSF has the strongest activity. And the activity of GDSF is stronger than EDSF.

The two step preparative synthesis of the DSFs followed the literature procedure. ${ }^{13-16}$ To a mixture of [bis-(2,2,2-trifluoroethoxy) phosporyl]methyl acetate $(1.1 \mathrm{mmol})$, and 18-C-6 / khmds hexamethyldisila-zylamine

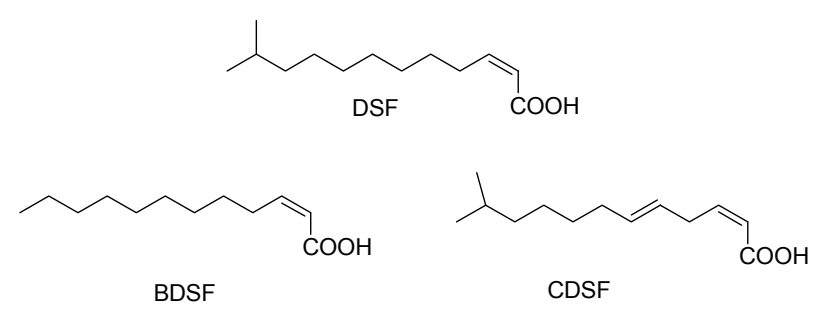

Fig. 1 - The structures of DSF, BDSF and CDSF. potassium (397 $\mathrm{mg}, 1.2 \mathrm{mmol}$ ) taken in round bottom flask was added $8 \mathrm{~mL}$ THF and the mixture was stirred at room temperature. The mixture was cooled to $-78^{\circ} \mathrm{C}$ by liquid nitrogen, and the mixture was added with $1.0 \mathrm{mmol}$ tetradecanal and the mixture was stirred continuously. The progress of reaction was checked by TLC. The reaction mixture was added saturated $\mathrm{NH}_{4} \mathrm{Cl}$ solution and the mixture was extracted three times with $20 \mathrm{~mL}$ ethyl acetate. The combined organic extracts were washed with water, dried over $\mathrm{Na}_{2} \mathrm{SO}_{4}$, and concentrated in a vacuum after filtration. Purification from column chromate- ography (the eluent was ethyl acetate $1 \mathrm{~mL}$ : petroleum ether $20 \mathrm{~mL}$ ) gave of light yellow liquid $\alpha$, $\beta$-Unsaturated enoic acid. In an ice bath, $1 \mathrm{mmol} \alpha, \beta$-Unsaturated enoic acid was quickly added to the mixture of $9 \mathrm{~mL}$ THF, 3 $\mathrm{mL}$ methanol, $3 \mathrm{~mL}$ water and $1.2 \mathrm{mmol} \mathrm{LiOH}$ with stir evenly, and the solution was maintained at $0{ }^{\circ} \mathrm{C}$. After 3 hours, the mixture was acidified with dilute hydrochloric acid. The mixture was extracted three times with $10 \mathrm{~mL}$ ethyl acetate. The combined organic extracts were washed with water, dried over $\mathrm{Na}_{2} \mathrm{SO}_{4}$, and concentrated in a vacuum after filtration to obtain light yellow liquid EDSF.

Repeating the experiment procedures, tetradecanal was replaced by corresponding tetradecanal or its homologue to give GDSF and FDSF.

(Z)-tetradec-2-enoic acid(EDSF), yield: 87\%. ESI/MS m/z: $226.2[\mathrm{M}+\mathrm{H}]^{+} .{ }^{1} \mathrm{H}$ NMR $\left(400 \mathrm{MHz}, \mathrm{CH}_{3} \mathrm{OD}\right) \delta: 6.27(\mathrm{~m}, 1 \mathrm{H}), 5.75(1 \mathrm{H}$, $\mathrm{d}, \mathrm{J}=11.6 \mathrm{~Hz}), 2.64\left(-\mathrm{C}_{2}-\mathrm{C}=\mathrm{C}-, 2 \mathrm{H}, \mathrm{m}\right)$, 1.30-1.47 (18H, m*), $0.91(3 \mathrm{H}, \mathrm{t}) ;{ }^{13} \mathrm{C}$ NMR (100 MHz, $\left.\mathrm{CH}_{3} \mathrm{OD}\right) \delta: 168.7,150.4,119.8$, $31.9,29.6,29.3,29.0,28.8,22.6,13.3$ (*the 8 methylene groups $\left(\mathrm{CH}_{2}\right)$ exhibiting overlapped signals)

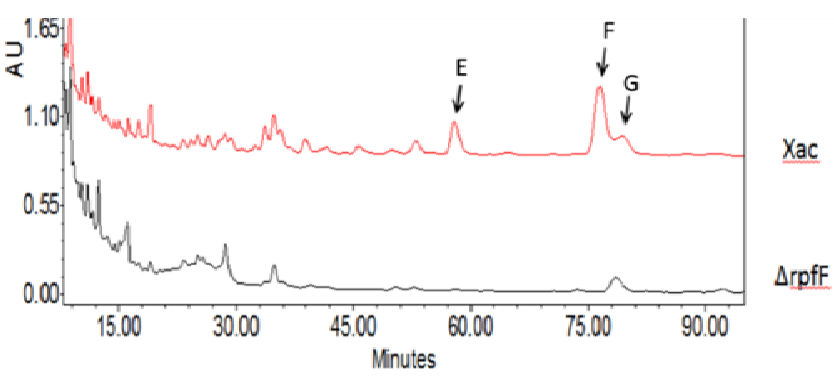

Fig. 2 - The HPLC spectra of Xac and $\Delta \mathrm{rpfF}$. 


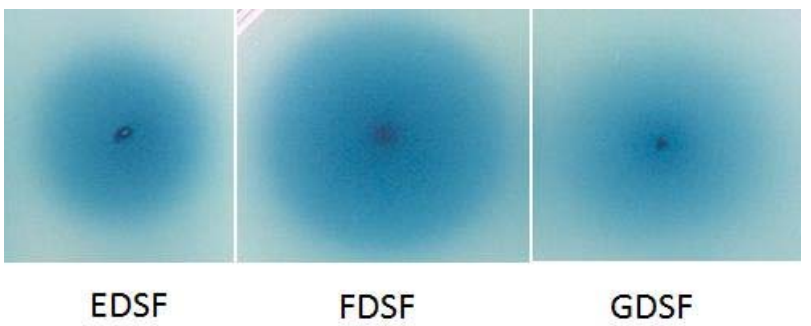

Fig. 3 - The compounds in fractions EDSF, FDSF and GDSF showed strong DSF-like activity. The X-gluc (40 mg) was dissolved in $1 \mathrm{~mL}$ DMSO to prepare the X-gluc solution, then the X-gluc solution $(400 \mu \mathrm{L} / 100 \mathrm{~mL})$ and FE58 report strain $(2 \mathrm{~mL} / 100 \mathrm{~mL})$ with OD600 of 2.0 were added to the NYG solid medium at about $42{ }^{\circ} \mathrm{C}$. It was pour into the culture dish, and placed for 15 minutes to solidify. After shading, the sample was placed flat in the $28^{\circ} \mathrm{C}$ incubator for $36 \mathrm{~h}$. The blue circle size was observed.

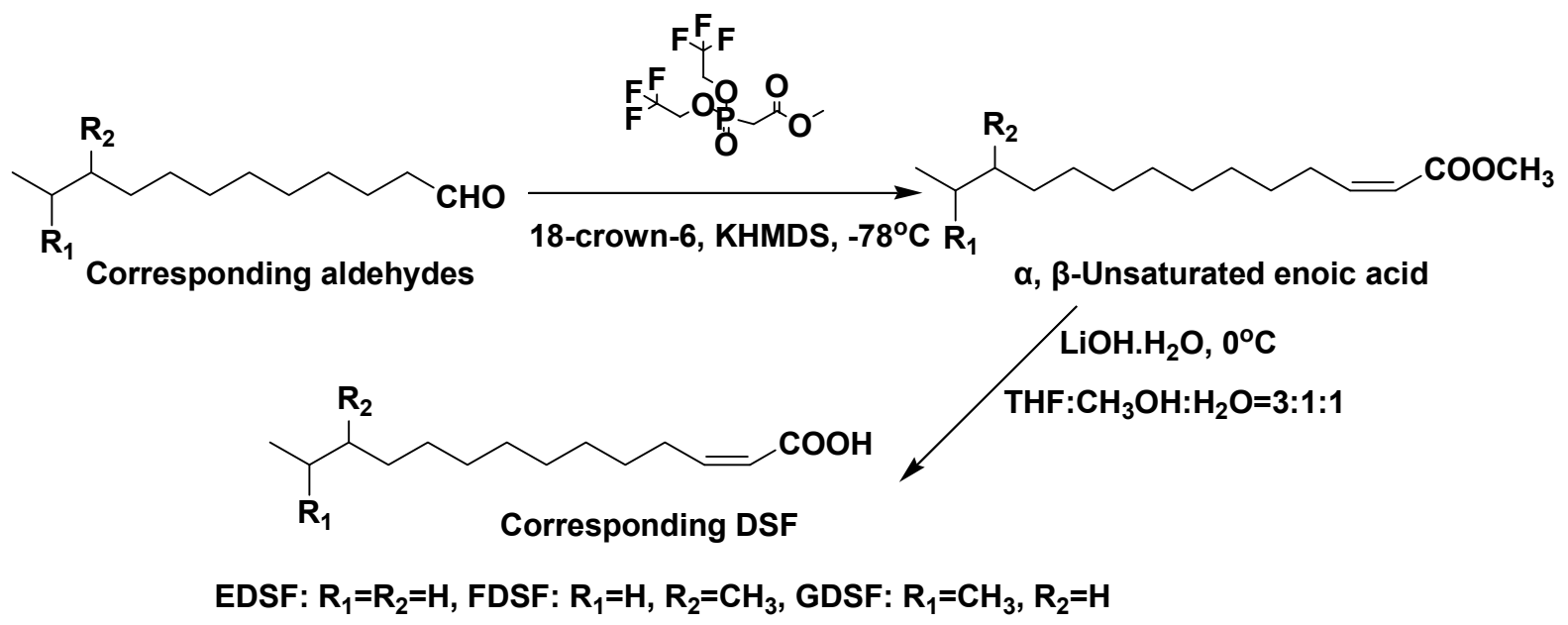

Scheme 1 - The pathway to synthesis of DSFs.

(Z)-13-methyl-tetradec-2-enoic

acid (GDSF), yield: $75 \%$. HRMS (ESI) calcd for $\mathrm{C}_{15} \mathrm{H}_{27} \mathrm{O}_{2} \quad$ 239.2017, $\quad[\mathrm{M}-\mathrm{H}]^{-}, \quad$ found 239.2010[M-H] ${ }^{-}{ }^{1} \mathrm{H}$ NMR (400 $\left.\mathrm{MHz}, \mathrm{CDCl}_{3}\right)$ $\delta: 6.37(1 \mathrm{H}, \mathrm{dt}, \mathrm{J}=9.12,2.8 \mathrm{~Hz}), 5.80(1 \mathrm{H} \mathrm{d}, \mathrm{J}$ $=11.6 \mathrm{~Hz}), 2.68 \quad\left(-\underline{\mathrm{C}}_{2}-\mathrm{C}=\mathrm{C}-, 2 \mathrm{H}, \quad \mathrm{m}\right)$, $1.16-1.56\left(17 \mathrm{H}, \mathrm{m}^{*}\right), 0.88(6 \mathrm{H}, \mathrm{d}, \mathrm{J}=6.8 \mathrm{~Hz})$; ${ }^{13} \mathrm{C}$ NMR $\left(100 \mathrm{MHz}, \mathrm{CDCl}_{3}\right) \delta: 172.0,153.6$, 119.0, 39.1, 30.0, 29.7, 29.6,29.4, 29.3, 29.2, 29.0, 28.0, 27.4, 22.7. (*the 8 methylene groups $\left(\mathrm{CH}_{2}\right)$ exhibiting overlapped signals)

(Z)-12-methyl-tetradec-2-enoic acid (FDSF), yield: $70 \%$. HRMS (ESI) calcd for $\mathrm{C}_{15} \mathrm{H}_{27} \mathrm{O}_{2}$, $239.2017[\mathrm{M}-\mathrm{H}]^{-}$, found $239.2009[\mathrm{M}-\mathrm{H}]^{-} .{ }^{1} \mathrm{H}$ NMR $\left(400 \mathrm{MHz}, \mathrm{CDCl}_{3}\right) \delta: 6.37(1 \mathrm{H}, \mathrm{m}), 5.80$ $(1 \mathrm{H}, \mathrm{d}, \mathrm{J}=11.2 \mathrm{~Hz}), 2.67\left(-\mathrm{CH}_{2}-\mathrm{C}=\mathrm{C}-, 2 \mathrm{H}, \mathrm{m}\right)$, 1.10-1.48 (17H, m*), $0.86\left(6 \mathrm{H}, \mathrm{m}^{* *}\right) ;{ }^{13} \mathrm{C}$ NMR $\left(100 \mathrm{MHz}, \mathrm{CDCl}_{3}\right) \delta: 172.5,153.6$, $119.1,36.7,34.4,30.0,29.6,29.5,29.4,29.3$, 29.2, 29.0, 27.1, 19.2, 11.4.( *the 8 methylene groups $\left(\mathrm{CH}_{2}\right)$ exhibiting overlapped signals; **there are overlapped signals on the two methyl groups, which was included the doublet of one methyl group is overlapping the triplet of the other)
In summary, two new kinds of active DSF family signal molecules (FDSF and GDSF) were successfully purified from culture supernatants of the $r p f C$ mutant Xac. FDSF was the most active. The DSFs were synthesized by 'two steps' with corresponding tetradecanal or its homologue as reaction substrate. Next, we will study the activity of FDSF in order to improve the production of citrus and reduce the harm to environment and human.

\section{REFERENCES}

1. R. P. Ryan and J. M. Dow, Trends in Microbiology, 2011, 19, 145-152.

2. B. Hongkai, Y. H. Yu, H. J Dong, H. H. Wang and J. E. Cronan, Mol Microbiol, 2014, 93, 262-275.

3. Y. P. Guo, Y. P. Zhang, J. L. Li and N. Wang, Mol. Plant. Microbe. Interact., 2012, 25, 165-179.

4. J. L. Tang, Y. N. Liu, C. E. Barber, J. M. Dow, J. C. Wootton and M. J. Daniels, Molec. Gen. Genetics, 1991, 226, 409-417.

5. C. E. Barber, J. L. Tang, J. X. Feng, M. Q. Pan, T. J. G. Wilson, H. Slater, J. M. Dow, P. Williams and M. J. Daniels, Molec. Microbiol., 1997, 24, 555-566. 
6. H. Slater, A. Alvarez-Morales, C. E. Barber, M. J. Daniels and J. M. Dow, Molec. Microbiol., 2000, 38, 986-1003.

7. L. H. Wang, Y. W. He, Y. Gao, J. E.Wu, Y. H. Dong, C. He, S. X. Wang, L. X., Weng, J. L. Xu, L., Tay, R. X. Fang, L. H. Zhang, Molecul. Microbiol., 2004, 51, 903-912.

8. L. Zhou, X. Y. Wang and Y. W. He, Scientia Agricultura Sinica, 2013, 46, 2910-2922.

9. Y. He, J. Wu, J. S. Cha and L. H. Zhang, BMC Microbiol., 2010, 10, 187-194.
10. Chongqing Academy of Chinese Materia Medica, China. Pat. CN 108911969 A, 2018.

11. G. T. Lu, J. Tang and J. Feng, J. Guang Xi Agric. Biol. Sci., 1993, 1, 10-14.

12. J. L. Tang, J. X. Feng and G. T. Lu, J. Zhejiang Agricul., 1998, 24, 528-536.

13. T. Keiko and K. Hiroshi, Org. Lett, 2000, 2, 1975-1978.

14. R. Rossi, C. Bechini, L. Mannina and P. Vergamini, Tetrahedron, 1998, 54, 135.

15. I. Nakamura and K. Harada, Heterocycles, 1978, 9, 473.

16. I. Paterson and I. Lyothier, Org. Lett, 2004, 6, 4933-4936. 